Article

\title{
Biosensor Using a One-Port Interdigital Capacitor: A Resonance-Based Investigation of the Permittivity Sensitivity for Microfluidic Broadband Bioelectronics Applications
}

\author{
Giovanni Crupi ${ }^{1, *}\left(\mathbb{C}\right.$, Xiue Bao ${ }^{2}\left(\mathbb{D}\right.$, Oluwatosin John Babarinde ${ }^{2}(\mathbb{D}$, \\ Dominique M. M.-P. Schreurs ${ }^{2}$ and Bart Nauwelaers ${ }^{2}$ \\ 1 Department of Biomedical and Dental Sciences and Morphofunctional Imaging, University of Messina, \\ 98125 Messina, Italy \\ 2 Electronic Engineering Department, KU Leuven, B-3001 Leuven, Belgium; xiue.bao@kuleuven.be (X.B.); \\ oluwatosinjohn.babarinde@kuleuven.be (O.J.B.); dominique.schreurs@kuleuven.be (D.M.M.-P.S.); \\ bart.nauwelaers@kuleuven.be (B.N.) \\ * Correspondence: crupig@unime.it; Tel.: +39-090-3977327
}

Received: 4 December 2019; Accepted: 13 February 2020; Published: 16 February 2020

\begin{abstract}
Electronics is a field of study ubiquitous in our daily lives, since this discipline is undoubtedly the driving force behind developments in many other disciplines, such as telecommunications, automation, and computer science. Nowadays, electronics is becoming more and more widely applied in life science, thus leading to an increasing interest in bioelectronics that is a major segment of bioengineering. A bioelectronics application that has gained much attention in recent years is the use of sensors for biological samples, with emphasis given to biosensors performing broadband sensing of small-volume liquid samples. Within this context, this work aims at investigating a microfluidic sensor based on a broadband one-port coplanar interdigital capacitor (IDC). The microwave performance of the sensor loaded with lossless materials under test (MUTs) is achieved by using finite-element method (FEM) simulations carried out with Ansoft's high frequency structure simulator (HFSS). The microfluidic channel for the MUT has a volume capacity of $0.054 \mu \mathrm{L}$. The FEM simulations show a resonance in the admittance that is reproduced with a five-lumped-element equivalent-circuit model. By changing the real part of the relative permittivity of the MUT up to 70, the corresponding variations in both the resonant frequency of the FEM simulations and the capacitance of the equivalent-circuit model are analyzed, thereby enabling assessment of the permittivity sensitivity of the studied IDC. Furthermore, it is shown that, although the proposed local equivalent-circuit model is able to mimic faithfully the FEM simulations locally around the resonance in the admittance, a higher number of circuit elements can achieve a better agreement between FEM and equivalent-circuit simulation over the entire broad frequency going range from $0.3 \mathrm{MHz}$ to $35 \mathrm{GHz}$.
\end{abstract}

Keywords: bioelectronics; bioengineering; equivalent circuit; microfluidic; microwave frequency; one-port interdigital capacitor; permittivity; sensor; sensitivity

\section{Introduction}

Bioelectronics is an interdisciplinary research field that bridges electronics and life sciences. The first steps of bioelectronics date back to Galvani's electrical experiments on frogs in the second half of the 18th century [1]. Over the years, this research field has continually evolved and nowadays is witnessing extraordinary progress, thus paving the way to the remarkable development in many bioelectronics applications, among which one of the most representative is the cardiac pacemaker. 
To underpin this rapid expansion, growing attention is being paid to the study and design of microwave electronics devices, circuits, and systems, thereby enabling the development of microwave electronics techniques oriented to applications in life sciences. In this context, a pivotal role is played by high-frequency sensors, going from radar systems (e.g., [2-6]) to biological sensors (e.g., [7-14]). Among the various applications in which high-frequency sensors can be useful, there is a significant use of microwave biological sensors in dielectric spectroscopy. By studying the interaction between electromagnetic fields and materials, dielectric spectroscopy can provide valuable insights into the frequency-dependent dielectric properties of a large variety of samples [15], like tissue [16], blood [17], proteins [18], and cultured cells [19]. The knowledge achieved in this way finds many applications, such as microwave imaging for cancer detection [20] and microwave hyperthermia for cancer therapy [21]. Compared to the traditional biosensing techniques based on optical and mechanical detection, high-frequency dielectric spectroscopy is very effective and attractive, due to notable benefits such as being label-free, non-invasive, contactless, rapid, and low cost [22]. The recent advances in microwave dielectric spectroscopy along with the progress in micro- and nanotechnologies have stimulated the development of miniature microwave biosensors for liquid characterization, enabling development in the lab-on-a-chip devices [23,24]. Microwave biological sensors for microliter and even nanoliter liquid samples find applications in many research fields, such as chemical synthesis, biological analysis, and medical diagnosis [25-32]. There has therefore been great interest in recent years in the development of miniature biosensors based on microwave dielectric spectroscopy analysis for liquid characterization. With this purpose, many efforts have been made in exploring the equivalent-circuit (EC) modeling of microwave microfluidic biosensors [33-40]. To deliver the microwave power to the microfluidic channel, the coplanar waveguide (CPW) technology is widely used, such as the CPW transmission line (CPW-TL) [25,41] and the CPW-fed interdigital capacitor (IDC) [12,30] with the channel integrated on the top surface. This is because the planar structures have the advantage of being easy to fabricate and integrate with microfluidic channels, especially when compared to bulky and expensive non-planar resonator structures.

To contribute to the advancement of this relevant and timely field of research, the present article is devoted to the extraction of an equivalent-circuit model and to the resonance-based investigation of the permittivity sensitivity, considering as case study a one-port coplanar interdigital capacitor (IDC) aimed at microfluidic broadband bioelectronics applications. Over the past few decades, interest in capacitors based on interdigital electrodes (IDE) has expanded from the traditional applications in communication systems [42] to the more recent ones in the biosensing field [12,30,37,43-46]. Although a few studies have been reported on exploiting this resonance of the IDC structure for biosensing purpose [45], the biomaterial characterization is advantageous at relatively low frequencies to avoid the onset of IDC self-resonance effects [37]. Nevertheless, different biological materials can show different dispersion properties at different frequency ranges, so it is necessary to analyze the spectroscopy of biological materials in a broad band. Broadband spectroscopy can be obtained by combing an IDC with a CPW line to avoid the onset of IDC self-resonance [28,47]. This method is time-consuming. Therefore, herein try to extend the IDC model to high frequencies to replace the use of CPW line for broadband measurements. It should be underlined that our results are purely based on simulations that are performed with finite-element and equivalent-circuit methods. The simulated biosensor consists of an SU-8 microfluidic structure aimed at the confinement of small volumes of samples in the CPW-IDC sensing region, gold sensing electrodes, and a quartz substrate. The SU-8 is used for the microfluidic channel as this is an inexpensive and biocompatible material. The gold is chosen as electrode material, as this noble metal is not harmful and does not adversely affect the physiology of biomaterials. The quartz is selected as substrate material owing to its great features, such as high optical transparence to a wide range of wavelengths, allowing visual inspection of the MUT with a microscope and even UV absorbance-based detection [48], high compatibility with various polymer materials, allowing more flexibility in the choice of microfluidic materials, low loss tangent, allowing achievement of low dielectric loss at microwave frequencies, and good thermal conductivity, allowing 
high operating temperatures. The practical sensing applications of the studied biosensor can go from permittivity to temperature characterization by using microwave dielectric spectroscopy analysis for monitoring the permittivity of a liquid and its temperature dependence. By placing many fingers in parallel, the interdigital (or interdigitated) layout allows one to increase the sensing area of the capacitive sensor and to minimize the parasitic resistive contributions [42,49]. The achieved increase in the capacitance results in turn in a lower resonant frequency, which is here exploited for sensing purpose. The main advantages of choosing a one-port device consist of allowing further sensor miniaturization and making experimental characterization simpler and faster, as it requires a one-port calibration that can be even done by connecting the sensor directly to a one-port vector network analyzer. The present investigation extends our previous work, by which the analysis has been limited to the pure IDC sensor (i.e., with air on top of the sensing area) that was designed using a finite-element method (FEM) simulator and, subsequently, modeled with a lumped-element equivalent-circuit [39]. Here, the capacitor sensing area (i.e., $450 \times 300 \mu \mathrm{m}^{2}$ ) is loaded with lossless materials under test (MUTs) having different values of the real part of the relative permittivity $\left(\varepsilon_{r}\right)$, spanning from 15 to 70 . The FEM simulations show that the presence of the MUT, in place of the air inside the channel, modifies the electrical characteristics and leads to the appearance of a resonance in the admittance that can exploited for detecting variations in $\varepsilon_{r}$. The determination of a five-lumped-element equivalent-circuit model enables a faithful reproduction of the FEM simulations, especially close to the resonant frequency. The impact of $\varepsilon_{r}$ on both resonant frequency and capacitance is investigated and then used to estimate quantitatively the sensor sensitivity. As will be shown later, the permittivity sensitivity of the tested IDC decreases with increasing $\varepsilon_{r}$ when using the resonant frequency as sensing parameter, while it is almost constant as a function of $\varepsilon_{r}$ when using the capacitance as sensing parameter. For the sake of completeness, a seven-lumped-element equivalent-circuit model is extracted to achieve a better agreement with the FEM simulations over the full frequency range, going from $0.3 \mathrm{MHz}$ to $35 \mathrm{GHz}$. However, although adding circuit elements leads a more powerful model, the five-element model offers a good compromise between model complexity and prediction accuracy, making it possible to use the extracted capacitance as a sensing parameter.

The remainder of this article is structured as follows. Section 2 is dedicated to the description of the studied biosensor. Section 3 is focused on the equivalent-circuit-based modeling of the permittivity-dependent resonance for sensitivity-based analysis. Section 4 discusses a modified version of the equivalent-circuit model for improving the model accuracy outside the frequency range of the resonance. Finally, Section 5 is devoted to the conclusions.

\section{Biosensor Description and FEM Simulations}

Figure 1 shows a top-view of the analyzed microfluidic sensor based on a one-port coplanar interdigital capacitor. The IDC sensor is studied using the 3D FEM analysis performed via Ansoft's high frequency structure simulator (HFSS). FEM simulations are performed in the frequency range from $0.3 \mathrm{MHz}$ to $35 \mathrm{GHz}$ with a step of $21.875 \mathrm{MHz}$.

Au electrodes are located on top of the quartz substrate having a dielectric constant and a loss tangent of 3.78 and 0, respectively. The thickness of the Au electrodes and quartz substrate are $600 \mathrm{~nm}$ and $1 \mathrm{~mm}$, respectively. An SU-8 layer is integrated on top of the IDC structure to form a microfluidic channel for the MUT. The thickness of the SU-8 microfluidic channel is $400 \mu \mathrm{m}$, thereby implying a MUT sensing height of $400 \mu \mathrm{m}$. The slot width, signal width, and finite ground width of the coplanar waveguide feeding line are $20 \mu \mathrm{m}, 110 \mu \mathrm{m}$, and $150 \mu \mathrm{m}$, respectively. This leads to a MUT sensing width of $450 \mu \mathrm{m}$ (i.e., $2 \times 20+110+2 \times 150 \mu \mathrm{m}$ ). There are, in total, 15 interdigitated fingers in the sensing area. The length of the fingers is $290 \mu \mathrm{m}$, whereas the finger width, the gap between fingers, and the gap at the end of each finger are all $10 \mu \mathrm{m}$. Therefore, the MUT sensing length is $300 \mu \mathrm{m}$ as it is defined as the sum between the finger length and the gap at the end of each finger. Consequently, the liquid volume within the microfluidic channel is $0.054 \mu \mathrm{L}$ (i.e., $450 \times 300 \times 400 \mu \mathrm{m}^{3}$ ). It should be underlined that the actual MUT sensing volume is even smaller. This is because the electric field does 
not extend $400 \mu \mathrm{m}$ above the IDC sensor and the most sensitive height above the sensing surface is about $20 \mu \mathrm{m}$ [37].

The FEM simulations are performed for the sensor loaded with lossless MUTs having a real part of the relative permittivity varied from 15 to 70 with a step of 5 . The achieved FEM results are then used for lumped EC model extraction, as will be discussed in the following two sections. To put this study into perspective with respect to the literature, Table 1 summarizes a comparison among different studies dealing with microfluidic IDC biosensors.

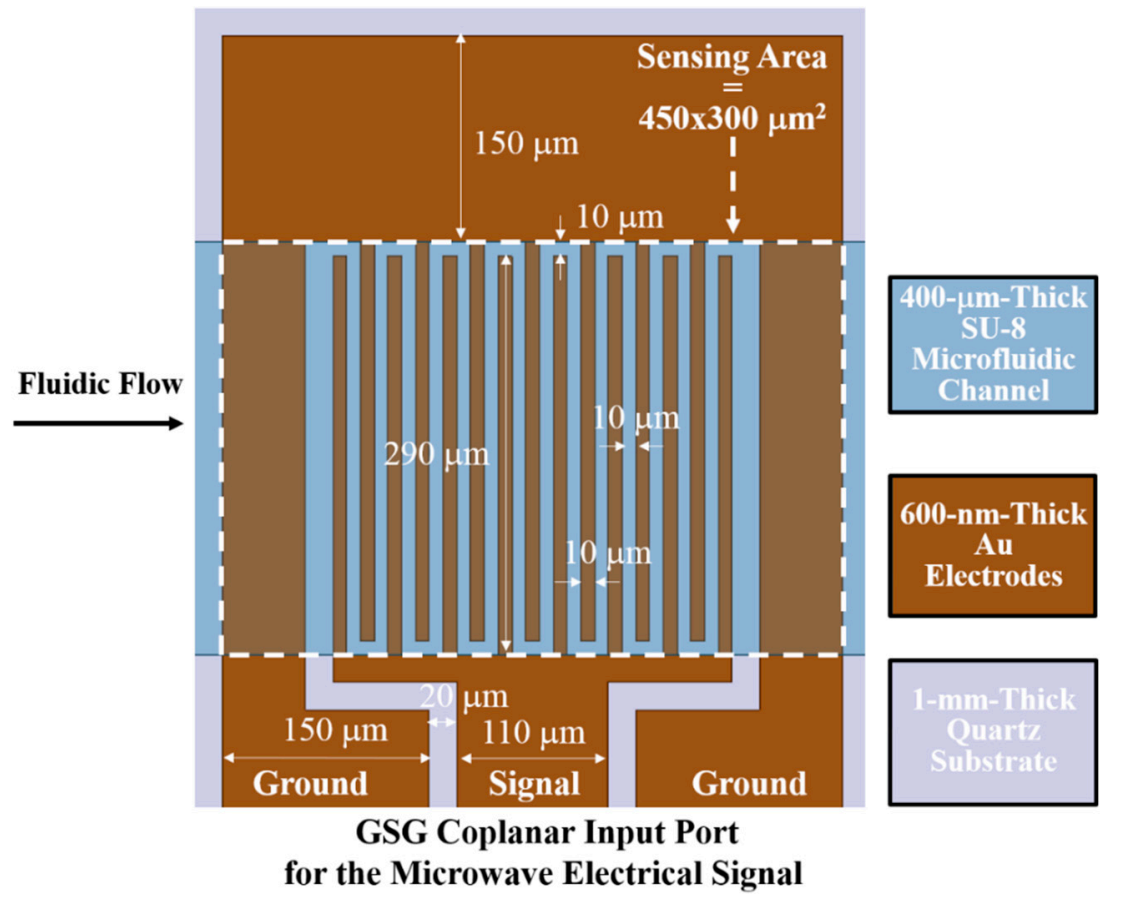

Figure 1. Top-view of the studied microfluidic biosensor based on one-port interdigital capacitor with 15 fingers in the sensing area.

Table 1. Comparison of various studies reporting on the investigation of fluidic IDC biosensors.

\begin{tabular}{|c|c|c|c|c|c|c|}
\hline Reference & $\begin{array}{c}\text { Channel-Electrode-Substrate } \\
\text { Materials }\end{array}$ & $\begin{array}{l}\text { Number } \\
\text { of Ports }\end{array}$ & Volume & $\begin{array}{l}\text { Analysis } \\
\text { Method }\end{array}$ & Frequency Range & MUT \\
\hline [34] & $\begin{array}{l}\text { PDMS- } \\
\text { Ti/Au- } \\
\text { Quartz }\end{array}$ & 2 & $0.9 \mathrm{~nL}$ & $\begin{array}{c}\text { FEM, EC } \\
\text { parameters, and } \\
\text { measurements }\end{array}$ & $40 \mathrm{MHz}-40 \mathrm{GHz}$ & $\begin{array}{l}\text { Alcohol-based } \\
\text { aqueous solutions } \\
\text { and fetal bovine } \\
\text { serum in water }\end{array}$ \\
\hline [47] & $\begin{array}{l}\text { PDMS- } \\
\text { Au- } \\
\text { Quartz }\end{array}$ & 2 & $<1 \mu \mathrm{L}$ & $\begin{array}{c}\text { FEM, EC } \\
\text { parameters, and } \\
\text { measurements }\end{array}$ & $100 \mathrm{~Hz}-40 \mathrm{GHz}$ & $\begin{array}{l}\text { De-ionized water } \\
\text { and methanol }\end{array}$ \\
\hline [12] & $\begin{array}{l}\text { PDMS- } \\
\text { Au- } \\
\text { Quartz }\end{array}$ & 1 & $1.2 \mathrm{~nL}$ & $\begin{array}{l}\text { FEM and } \\
\text { measurements }\end{array}$ & $\begin{array}{c}7.8 \mathrm{GHz}-8.4 \mathrm{GHz} \\
\& @ 25 \mathrm{GHz}\end{array}$ & $\begin{array}{l}\text { Water-isopropanol } \\
\text { mixture }\end{array}$ \\
\hline [46] & $\begin{array}{c}\text { SU-8- } \\
\text { Au- } \\
\text { Quartz }\end{array}$ & 2 & $0.1 \mu \mathrm{L}$ & $\begin{array}{c}\text { FEM, EC } \\
\text { parameters, and } \\
\text { measurements }\end{array}$ & $10 \mathrm{MHz}-50 \mathrm{GHz}$ & $\begin{array}{l}\text { De-ionized water } \\
\text { and saline } \\
\text { solutions }\end{array}$ \\
\hline [28] & $\begin{array}{c}\text { SU-8- } \\
\text { Au- } \\
\text { Quartz }\end{array}$ & 1 & $0.09 \mu \mathrm{L}$ & $\begin{array}{c}\text { FEM, EC } \\
\text { parameters, and } \\
\text { measurements }\end{array}$ & $300 \mathrm{kHz}-50 \mathrm{GHz}$ & $\begin{array}{l}\text { Yeast cell culture } \\
\text { and mammalian } \\
\text { cell culture }\end{array}$ \\
\hline [Here] & $\begin{array}{c}\text { SU-8- } \\
\text { Au- } \\
\text { Quartz }\end{array}$ & 1 & $0.054 \mu \mathrm{L}$ & $\begin{array}{l}\text { FEM and EC } \\
\text { parameters }\end{array}$ & $0.3 \mathrm{MHz}-35 \mathrm{GHz}$ & $\begin{array}{l}\text { Lossless MUTs } \\
\text { with different } \varepsilon_{r}\end{array}$ \\
\hline
\end{tabular}




\section{Equivalent-Circuit-Based Modeling and Sensitivity-Based Analysis}

As reported in [39], the lumped-element equivalent-circuit model of the studied pure IDC sensor consists of the parallel connection of the $R_{1} L_{1} C_{1}$ series and the $R_{2} C_{2}$ series (see Figure 2). The extracted element values with air as MUT are: $R_{1}=1.57 \Omega, L_{1}=83.81 \mathrm{pH}, C_{1}=60.47 \mathrm{fF}, R_{2}=21.12 \mathrm{k} \Omega$, and $C_{2}=3.46 \mathrm{fF}$. The three elements $R_{1}, L_{1}$, and $C_{1}$ represent the resistive, inductive, and capacitive contributions of the multi-finger structure, respectively. The $R_{2} C_{2}$ network was added in parallel with the $R_{1} L_{1} C_{1}$ network to reproduce the FEM simulations showing a remarkable increase of $\operatorname{Re}(Z)$ with decreasing frequency, since the $R_{1} L_{1} C_{1}$ series is able to reproduce only a frequency-independent $\operatorname{Re}(Z)$

$$
Z=R_{1}+j\left(\omega L_{1}-\frac{1}{\omega C_{1}}\right) .
$$

The physical origin of $C_{2}$ was ascribed to the capacitive coupling between fingers and ground (i.e., the lateral grounds of the coplanar ground-signal-ground structure as underneath the substrate there is no bottom ground) through the quartz substrate and/or air and $R_{2}$ was used to introduce a time constant associated with the dispersion of this coupling. It is worth noticing that $C_{1}$, representing the capacitive coupling between the fingers, was found to be much larger than $C_{2}$, representing the capacitive coupling between fingers and ground. This is consistent with the fact that the distance between the fingers is much smaller than the distance between fingers and ground. The modeling procedure was successfully validated for the case of air as MUT, through the comparison between FEM and equivalent-circuit simulations over the full studied frequency range [39].

From Equation (1), it follows that the admittance of the $R_{1} L_{1} C_{1}$ series is given by

$$
Y=\frac{R_{1}}{R_{1}^{2}+\left(\omega L_{1}-\frac{1}{\omega C_{1}}\right)^{2}}-j \frac{\left(\omega L_{1}-\frac{1}{\omega C_{1}}\right)}{R_{1}^{2}+\left(\omega L_{1}-\frac{1}{\omega C_{1}}\right)^{2}} .
$$

This equation highlights that a resonance should occur when the inductive and the capacitive reactances of the $R_{1} L_{1} C_{1}$ series cancel each other, leading to a resonant frequency $\left(f_{r}\right)$ given by

$$
f_{r}=\frac{1}{2 \pi \sqrt{L_{1} C_{1}}} .
$$

When the frequency reaches $f_{r}, \operatorname{Re}(Y)$ should exhibit a peak equal to the inverse of $R_{1}$ and $\operatorname{Im}(Y)$ should become equal to zero. The admittance of the sensor can be modeled by using only the $R_{1} L_{1} C_{1}$ network at the resonant frequency, since this network reduces to only $R_{1}$ that is then connected in parallel to the rest of the circuit having a larger impedance. Nevertheless, this resonance of the $R_{1} L_{1} C_{1}$ series was not observed in the FEM simulations of the pure IDC sensor [39], since both Equation (3) based on only the $R_{1} L_{1} C_{1}$ network and the five-element equivalent-circuit simulations show that the resonance occurs at $70.7 \mathrm{GHz}$ which is far beyond the upper frequency limit of the FEM simulations. In the present study, the real part of the relative permittivity of the MUT is increased enough to make the resonance observable, by exploiting the fact that a higher $\varepsilon_{r}$ leads to a larger $C_{1}$ and, consequently, smaller $f_{r}$ (see Equation (3)). A higher $\varepsilon_{r}$ implies a larger $C_{1}$, since this element represents the capacitive coupling of the multi-finger structure through the quartz substrate and air for the pure IDC sensor but, when a MUT is placed on top of the sensing area, the capacitive coupling through the MUT should be taken into account in the estimation of $C_{1}$. As illustrated in Figure 3, the sensor resonant frequency can be defined as the frequency at which the admittance has a peak in the real part and zero imaginary part. The FEM simulations show that, by increasing the real part of the relative permittivity of the MUT, the resonant frequency shifts towards lower values and, in addition, the peak in $\operatorname{Re}(Y)$ becomes progressively higher. The achieved results are illustrated in Figure 4 . The observed reduction of the resonant peak in $\operatorname{Re}(Y)$ at lower $\varepsilon_{r}$ might be correlated to the skin effect of the metallization of the multi-finger structure [50], implying an increase of the resistive contributions at higher frequencies. 
To assess the sensing performance of the tested IDC as an $\varepsilon_{r}$ sensor, the absolute $\left(S_{f r}\right)$ and relative $\left(R S_{f r}\right)$ sensitivity of $f_{r}$ to changes in $\varepsilon_{r}$ are calculated by using a reference $\varepsilon_{r}\left(\varepsilon_{r o}\right)$ of 15

$$
\begin{gathered}
S_{f r}=\frac{\Delta f_{r}}{\Delta \varepsilon_{r}}=\frac{f_{r}-f_{r o}}{\varepsilon_{r}-\varepsilon_{r o}}, \\
R S_{f r}=100 \frac{\Delta f_{r}}{f_{r o} \Delta \varepsilon_{r}} .
\end{gathered}
$$

As should be expected from the fact that $f_{r}$ decreases with increasing $\varepsilon_{r}$, both $S_{f r}$ and $R S_{f r}$ are negative and their magnitudes are reduced with increasing $\varepsilon_{r}$ (see Figure 5 ). $S_{f r}$ reaches its maximum magnitude of $0.638 \mathrm{GHz} / \Delta 1$ when $\varepsilon_{r}$ is 20, implying that a variation in $\varepsilon_{r}$ value of 5 can be detected as a variation in $f_{r}$ value of $3.19 \mathrm{GHz}$.

The values of $C_{1}$ can be straightforwardly determined from $f_{r}$, since the inductance can be assumed to be independent of $\varepsilon_{r}$

$$
C_{1}=\frac{1}{\left(2 \pi f_{r}\right)^{2} L_{1}}
$$

In line with the expectations [37], Figure 6 shows that the extracted $C_{1}$ exhibits a linear increase with increasing $\varepsilon_{r}$. Likewise to $S_{f r}$ and $R S_{f r}$, the absolute $\left(S_{C 1}\right)$ and relative $\left(R S_{C 1}\right)$ sensitivity of $C_{1}$ to changes in $\varepsilon_{r}$ can be calculated as

$$
\begin{gathered}
S_{C 1}=\frac{\Delta C_{1}}{\Delta \varepsilon_{r}}, \\
R S_{C 1}=100 \frac{\Delta C_{1}}{C_{10} \Delta \varepsilon_{r}} .
\end{gathered}
$$

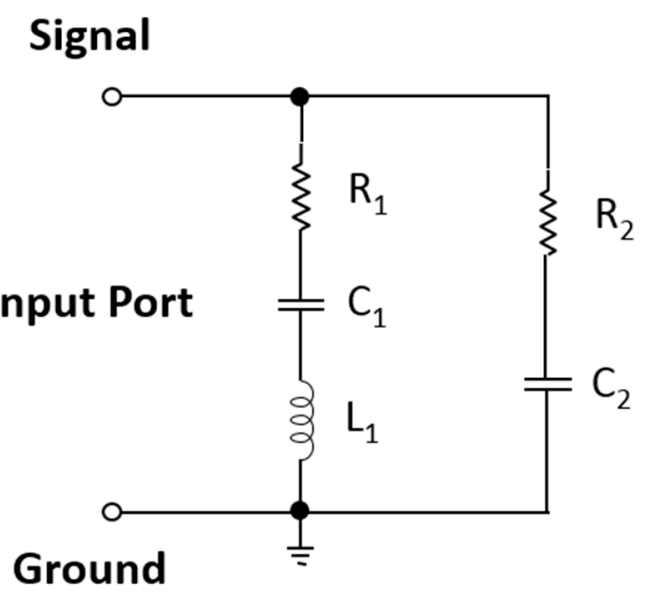

Figure 2. Equivalent circuit for the studied microfluidic IDC sensor. 


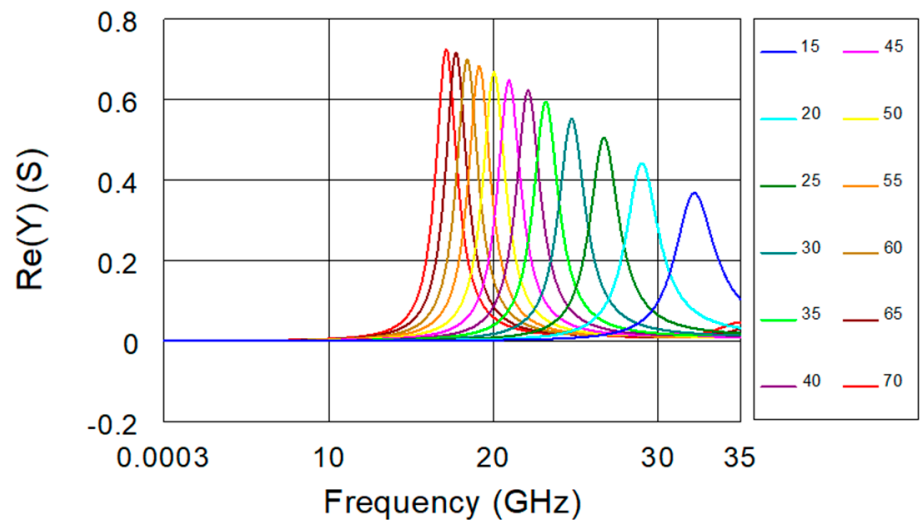

(a)

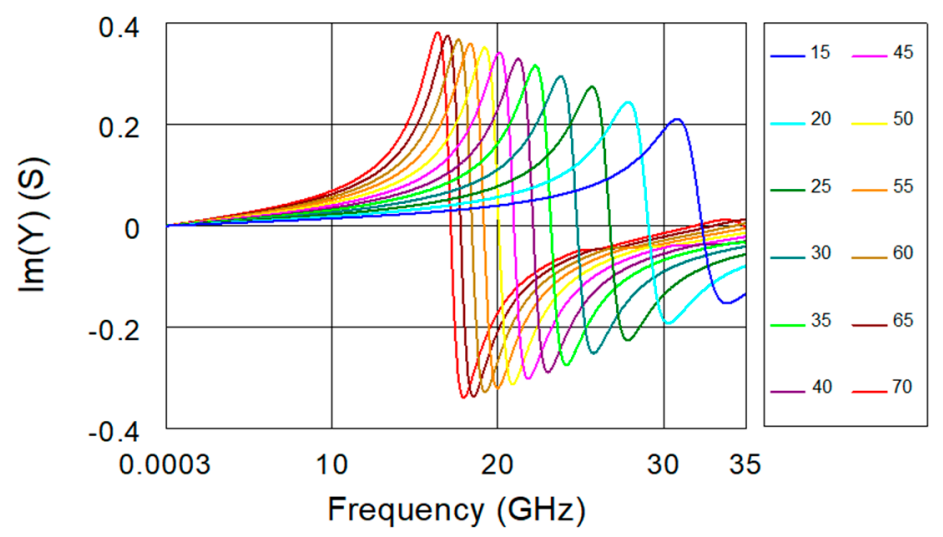

(b)

Figure 3. FEM simulations of the (a) real and (b) imaginary parts of the admittance from $0.3 \mathrm{MHz}$ to 35 GHz for the IDC sensor loaded with lossless MUTs having a real part of the relative permittivity varied from 15 to 70 with a step of 5 .

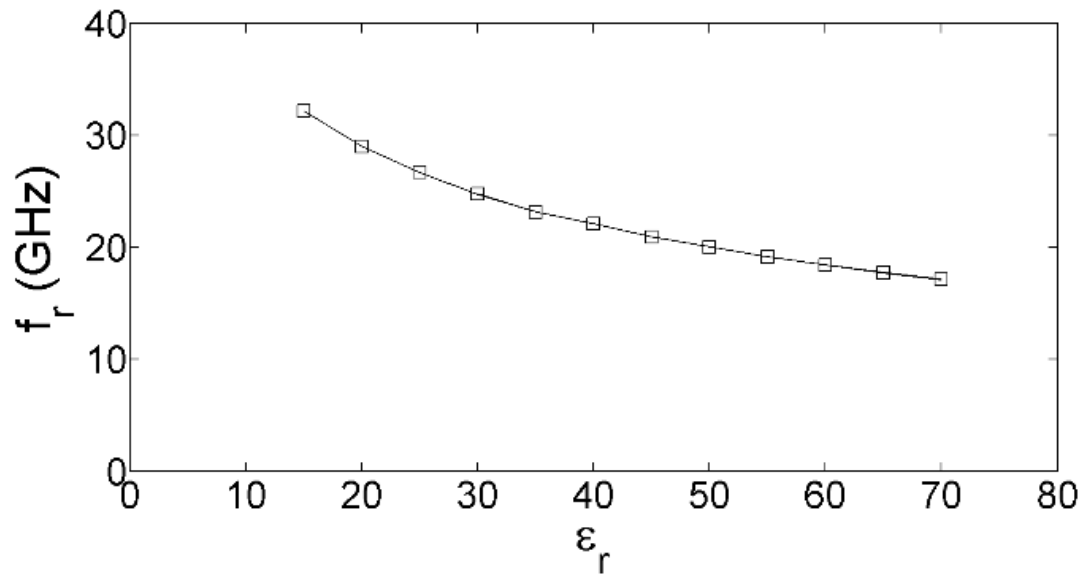

(a)

Figure 4. Cont. 


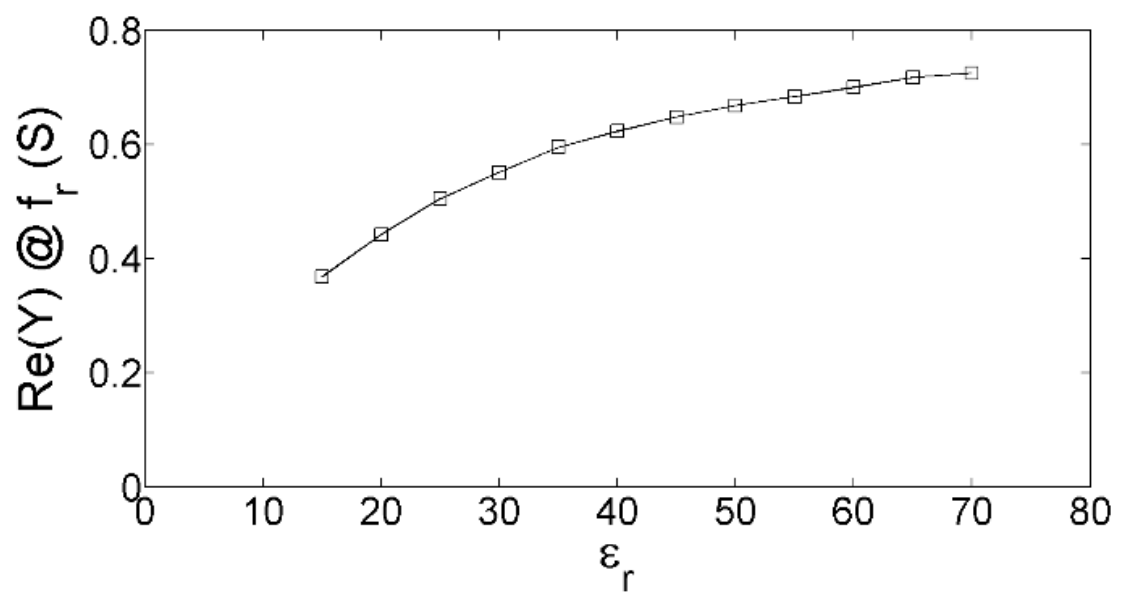

(b)

Figure 4. Behavior of the (a) resonant frequency and corresponding (b) peak in $\operatorname{Re}(Y)$ versus $\varepsilon_{r}$ for the lossless MUTs placed on top of the sensing area of the IDC sensor.

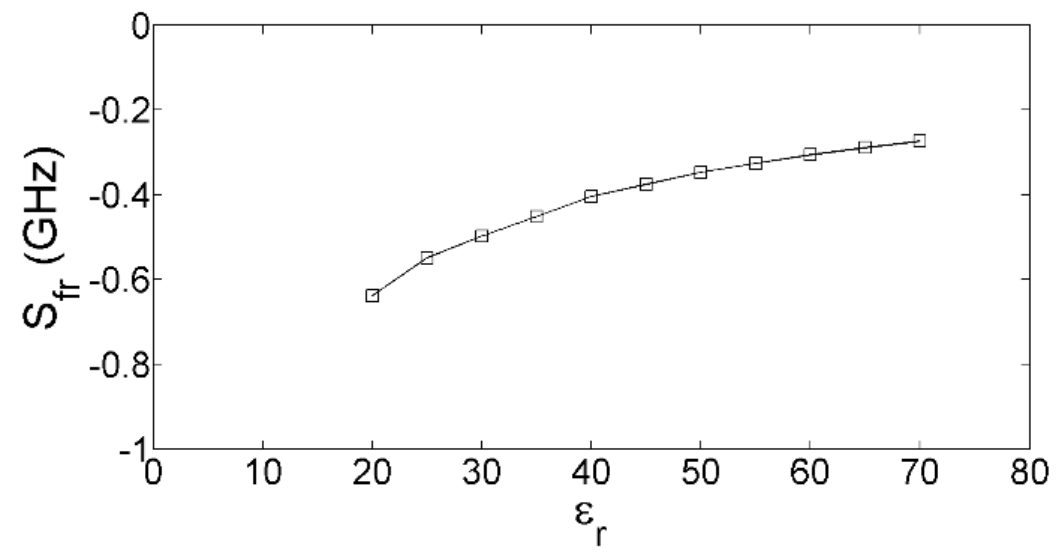

(a)

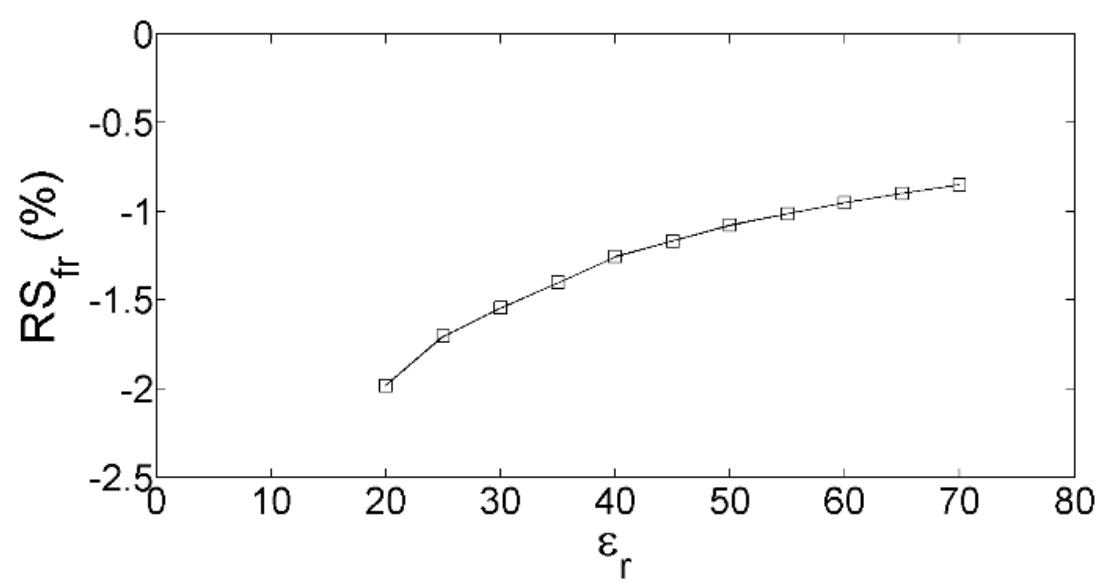

(b)

Figure 5. Behavior of the (a) absolute and (b) relative sensitivity of $f_{r}$ to variations in $\varepsilon_{r}$ for the lossless MUTs placed on top of the sensing area of the IDC sensor. When $\varepsilon_{r}$ is $20, S_{f r}$ and $R S_{f r}$ reach their maximum magnitude of $0.638 \mathrm{GHz} / \Delta 1$ and $1.98 \%$, respectively. 


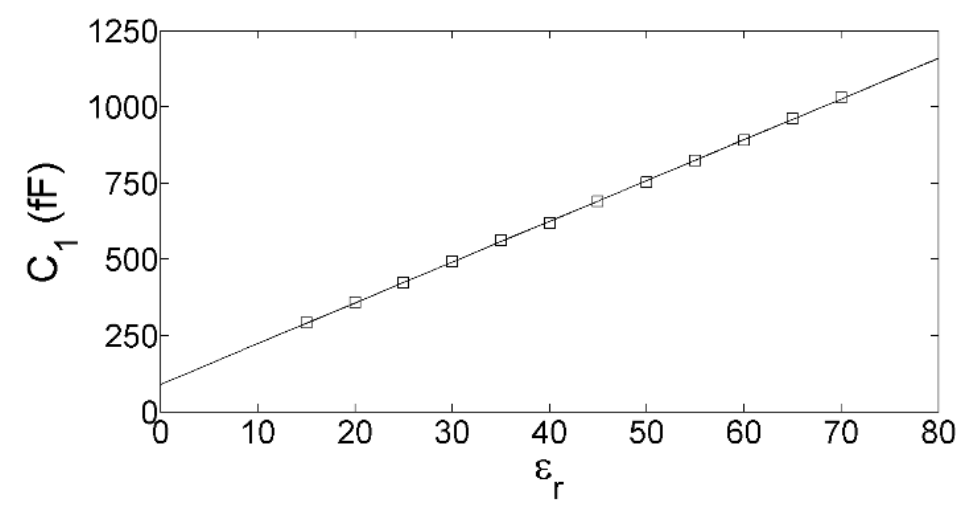

Figure 6. Behavior of $C_{1}$ versus $\varepsilon_{r}$ with the approximating straight line for the lossless MUTs placed on top of the sensing area of the IDC sensor.

As should be expected from the fact that $C_{1}$ increases linearly with increasing $\varepsilon_{r}$, both $S_{C 1}$ and $R S_{C 1}$ are positive and practically insensitive to $\varepsilon_{r}$ (see Figure 7). The average values of $S_{C 1}$ and $R S_{C 1}$ are $13.35 \mathrm{fF} / \Delta 1$ and $4.58 \%$, respectively. The good linear relationship between $C_{1}$ and $\varepsilon_{r}$ implies that the average value of $S_{C 1}$ is almost equal to the slope of the approximating straight line (i.e., $13.37 \mathrm{fF}$ ).

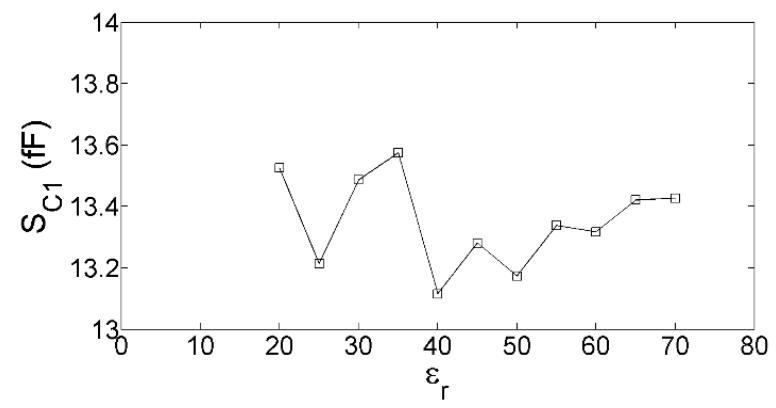

(a)

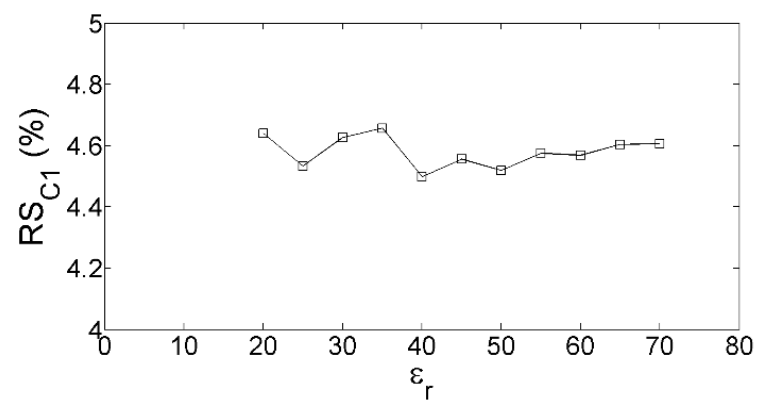

(b)

Figure 7. Behavior of the (a) absolute and (b) relative sensitivity of $C_{1}$ to variations in $\varepsilon_{r}$ for the lossless MUTs placed on top of the sensing area of the IDC sensor. The average values of $S_{C 1}$ and $R S_{C 1}$ are $13.35 \mathrm{fF} / \Delta 1$ and $4.58 \%$, respectively.

To enable the lumped-element equivalent circuit to reproduce faithfully the resonance in the admittance of the sensor loaded with MUTs, $C_{1}$ is extracted from $f_{r}$ (see Equation (6)) and $R_{1}$ is set equal to the inverse of the resonant peak in $\operatorname{Re}(Y)$. As a few illustrative examples, Figure 8 reports the good agreement between the FEM and equivalent-circuit simulations of the resonance affecting the admittance of the sensor at the lowest, highest, and at a middle value of $\varepsilon_{r}$. Although some discrepancies might be observed as the frequency departs from the resonant frequency, the extracted 
model can accurately mimic the FEM simulations locally around the resonance in the admittance, thus enabling the use of this biosensor for $\varepsilon_{r}$ sensing.

For the sake of completeness, Table 2 lists the values of $f_{r}$ and $\operatorname{Re}(Y) @ f_{r}$, which were obtained from the FEM simulations performed by considering the microfluidic biosensor loaded with a MUT having different $\varepsilon_{r}$ (see Figure 1), and the corresponding extracted values of $C_{1}$ and $R_{1}$, which were used for performing the $\varepsilon_{r}$-dependent simulations of the achieved equivalent-circuit model.

Table 2. Values of $f_{r}, \operatorname{Re}(Y) @ f_{r}, C_{1}$, and $R_{1}$ as a function of $\varepsilon_{r}$.

\begin{tabular}{ccccc}
\hline$\varepsilon_{r}$ & $f_{r}(\mathbf{G H z})$ & $\operatorname{Re}(\boldsymbol{Y}) @ f_{r}(\mathbf{S})$ & $C_{\boldsymbol{1}}(\mathbf{f F})$ & $\boldsymbol{R}_{\mathbf{1}}(\boldsymbol{\Omega})$ \\
\hline 15 & 32.20 & 0.368 & 291.5 & 2.72 \\
20 & 29.01 & 0.442 & 359.1 & 2.26 \\
25 & 26.71 & 0.505 & 423.6 & 1.98 \\
30 & 24.74 & 0.551 & 493.8 & 1.81 \\
35 & 23.17 & 0.595 & 563.0 & 1.68 \\
40 & 22.09 & 0.623 & 619.4 & 1.61 \\
45 & 20.93 & 0.648 & 689.9 & 1.54 \\
50 & 20.04 & 0.668 & 752.6 & 1.50 \\
55 & 19.14 & 0.684 & 825.0 & 1.46 \\
60 & 18.42 & 0.700 & 890.8 & 1.43 \\
65 & 17.72 & 0.717 & 962.5 & 1.39 \\
70 & 17.13 & 0.725 & 1030.0 & 1.38 \\
\hline
\end{tabular}

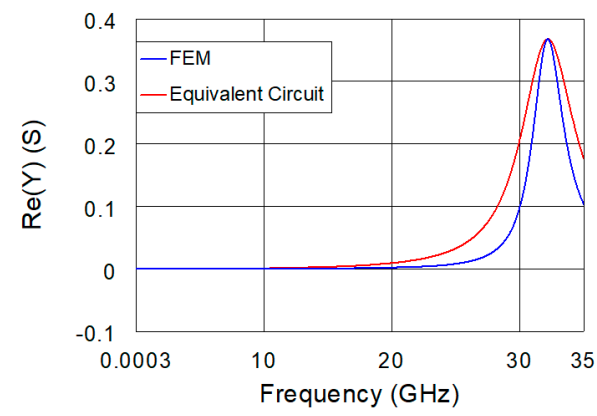

(a)

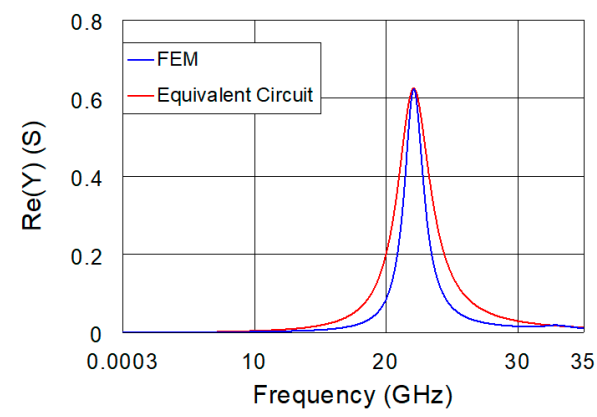

(c)

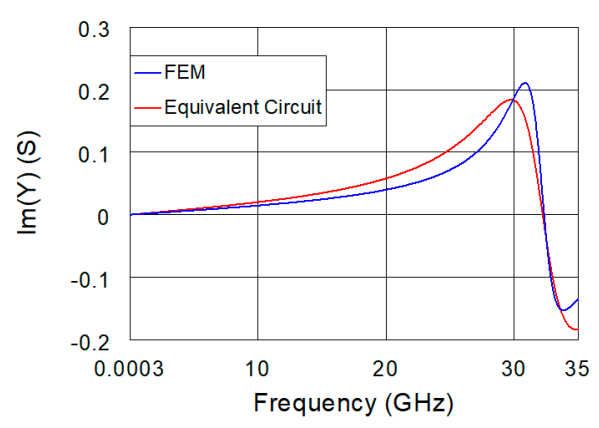

(b)

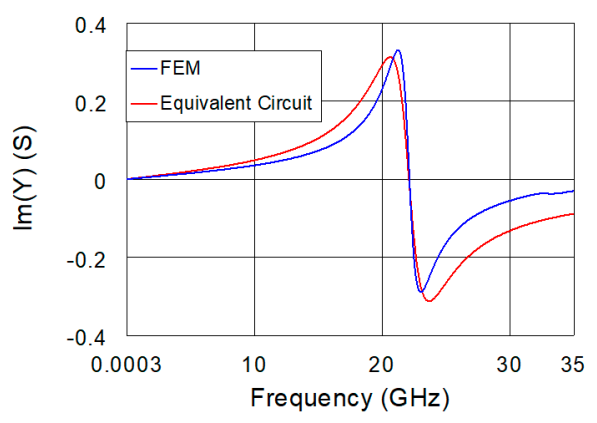

(d)

Figure 8. Cont. 


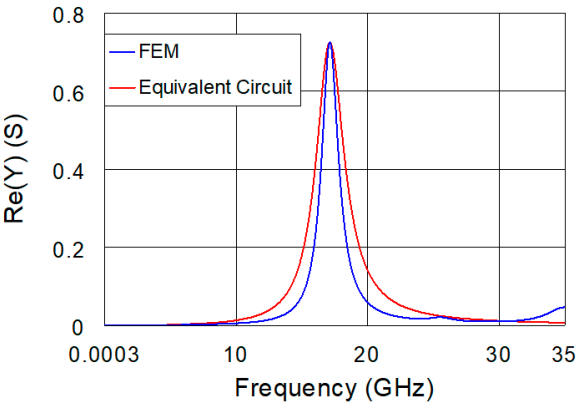

(e)

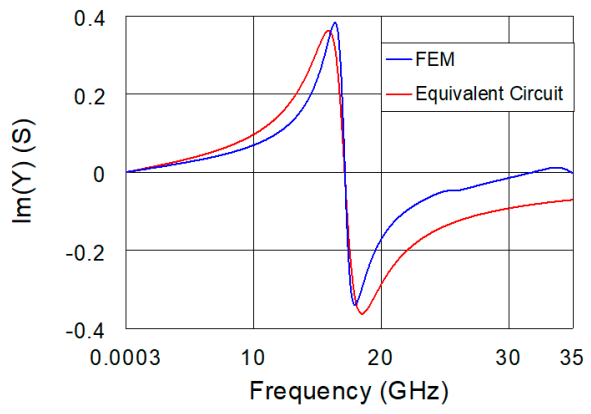

(f)

Figure 8. FEM (blue lines) and equivalent-circuit (red lines) simulations of the $(\mathbf{a}, \mathbf{c}, \mathbf{e})$ real and $(\mathbf{b}, \mathbf{d}, \mathbf{f})$ imaginary parts of the admittance from $0.3 \mathrm{MHz}$ to $35 \mathrm{GHz}$ for the IDC sensor loaded with lossless MUTs having a real part of the relative permittivity of $(\mathbf{a}, \mathbf{b}) 15 ;(\mathbf{c}, \mathbf{d}) 40$; and $(\mathbf{e}, \mathbf{f}) 70$.

\section{Modified Version of the Equivalent Circuit}

For the sake of completeness, it is worthy noticing that the model needs to be modified to mimic the admittance and its corresponding impedance over the full frequency range of the FEM simulations. As an illustrative example, Figure 9 a shows that $\operatorname{Re}(Z)$ first decreases, then stays constant, next increases, and finally decreases again for MUTs with higher $\varepsilon_{r}$. The low-frequency reduction of $\operatorname{Re}(Z)$ can be reproduced by selecting appropriate values of $R_{2}$ and $C_{2}$, whereas the high-frequency behavior in $\operatorname{Re}(Z)$ implies that the model complexity should be increased. As a matter of fact, an $R_{3} C_{3}$ series should be added in parallel to the circuit to allow mimicking the high-frequency behavior of $\operatorname{Re}(Z)$ (see Figure 10). To give an illustrative example, Figure 11 shows that, by manually tuning the values of $R_{2}, C_{2}, R_{3}$, and $C_{3}$, the model is able to reproduce the behavior of the impedance over the full studied frequency range, including the low-frequency decrease, the high-frequency increase, and the final decrease of $\operatorname{Re}(Z)$. The values of the extracted elements are: $R_{1}=1.38 \Omega, L_{1}=83.81 \mathrm{pH}, C_{1}=1030 \mathrm{fF}$, $R_{2}=7 \mathrm{k} \Omega, C_{2}=200 \mathrm{fF}, R_{3}=0.5 \Omega$, and $C_{3}=430 \mathrm{fF}$. The physical origin of the $R_{3} C_{3}$ network might be ascribed to the high-frequency skin-effect losses, deviations further away from TEM-like propagation (e.g., surface-wave modes leading to high-frequency losses and dispersion as a result of the dielectric mismatch), and limitations of the lumped-element approximation at higher frequencies. It should be highlighted that, analogously to the fact that the studied IDC sensor loaded with a MUT having high $\varepsilon_{r}$ exhibits a peak in $\operatorname{Re}(Z)$ at frequencies beyond the resonant frequency of the admittance, large (field-effect transistors) FETs based on multi-finger lay-out exhibit a peak in the real part of each impedance parameter at frequencies beyond the cutoff frequency $\left(f_{T}\right)$, turning into a current-gain peak and originating from a resonance of the extrinsic reactive elements [51,52].

To estimate the discrepancies between FEM and equivalent-circuit simulations, Figure 12 shows the frequency dependence of the difference between FEM and equivalent-circuit simulations of the real and imaginary parts of the admittance for the case with a real part of the relative permittivity of 70. As can be observed, although the use of the modified broadband model enables reduction of the discrepancies over the extremely wide frequency range, the local model can keep discrepancies very small locally around the resonance in the admittance.

As a final remark, it can be highlighted that, although a higher number of circuit elements can help to achieve a more powerful model, the local model proposed in the previous section represents a good trade-off between complexity and accuracy, enabling an accurate and straightforward reproduction of the sensor resonance and then determination of the permittivity sensitivity by using the extracted capacitance $C_{1}$ as sensing parameter. 


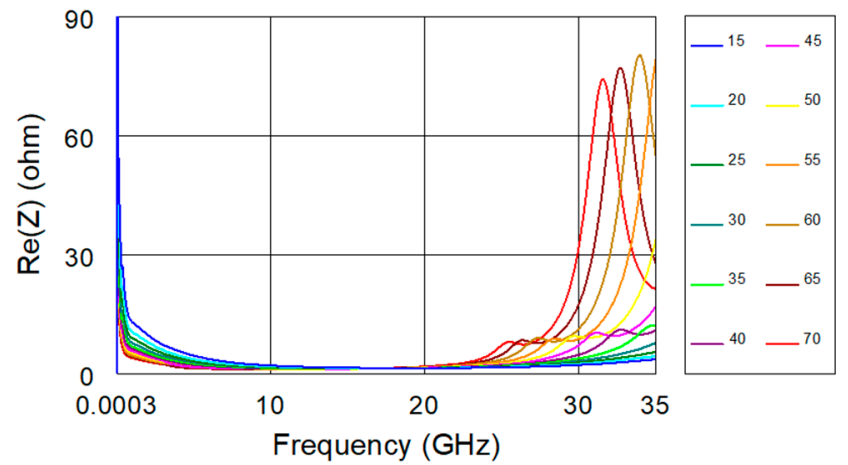

(a)

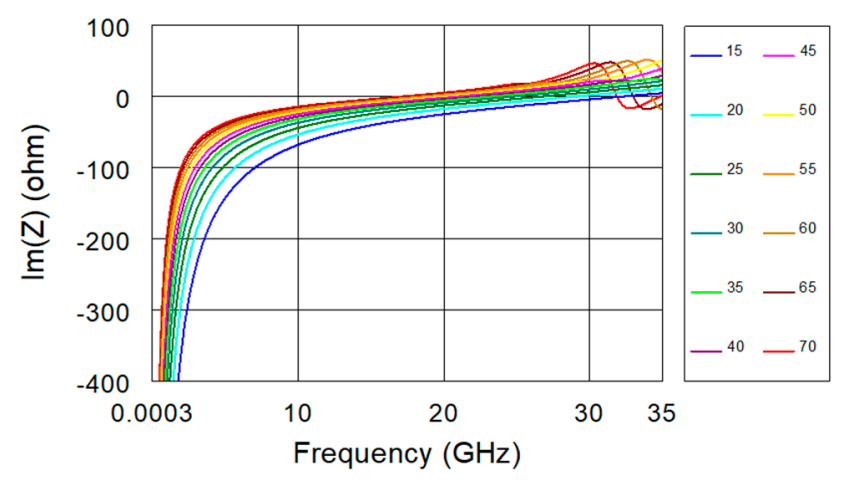

(b)

Figure 9. FEM simulations of the (a) real and (b) imaginary parts of the impedance from $0.3 \mathrm{MHz}$ to $35 \mathrm{GHz}$ for the IDC sensor loaded with lossless MUTs having a real part of the relative permittivity varied from 15 to 70 with a step of 5 .

\section{Signal}

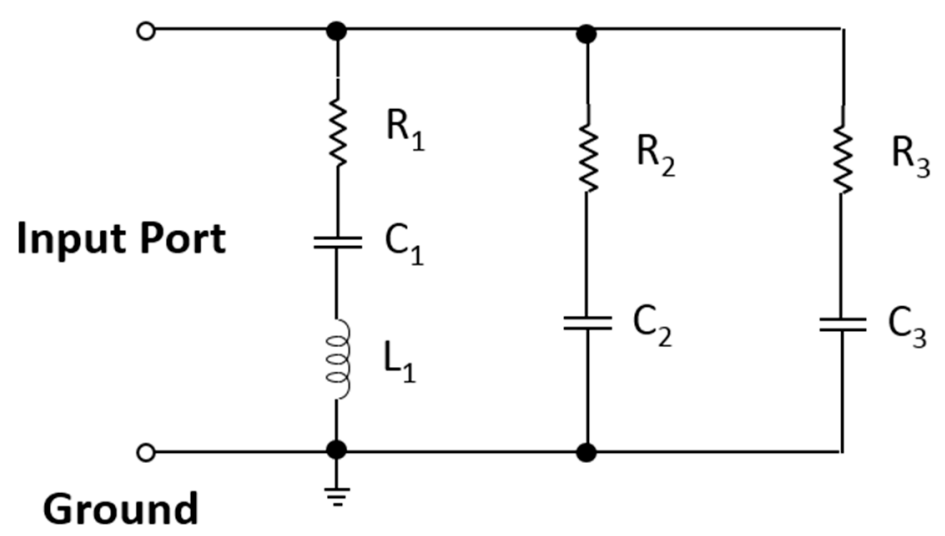

Figure 10. A modified version of the equivalent circuit for the studied microfluidic IDC sensor. 


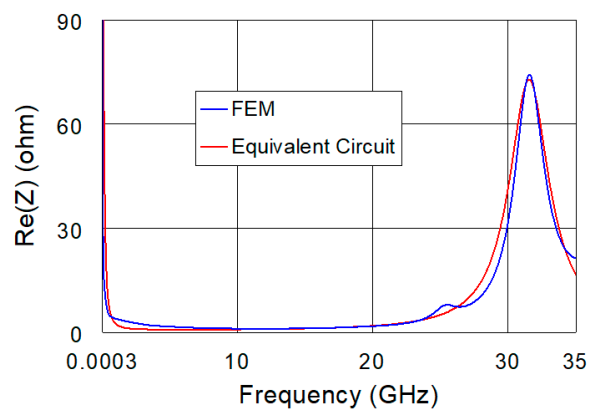

(a)

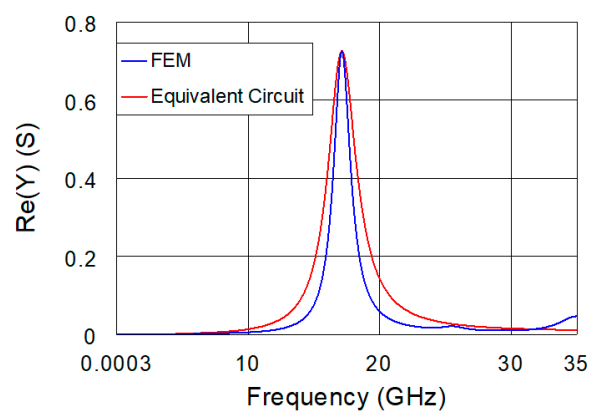

(c)

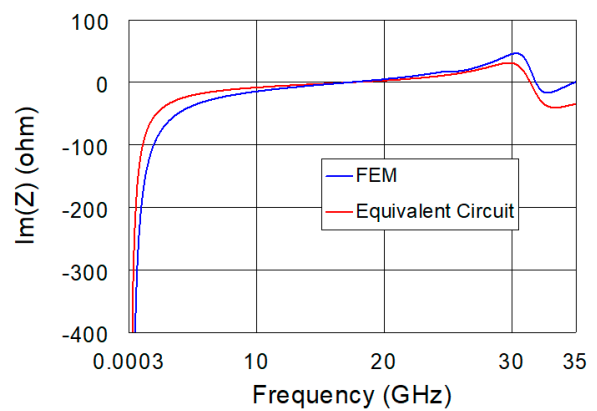

(b)

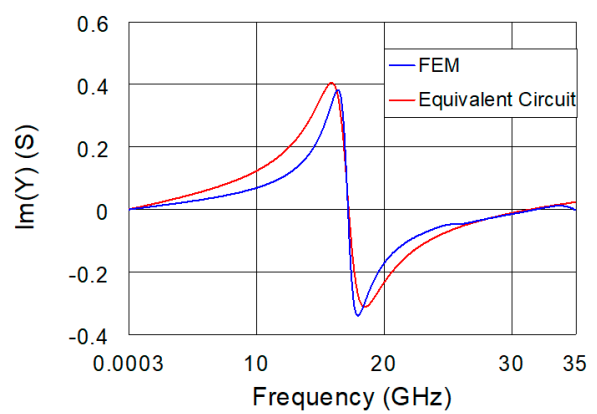

(d)

Figure 11. FEM (blue lines) and equivalent-circuit (red lines) simulations of the real and imaginary parts of the (a,b) impedance and (c,d) admittance from $0.3 \mathrm{MHz}$ to $35 \mathrm{GHz}$ for the IDC sensor loaded with lossless MUT having a real part of the relative permittivity of 70 .

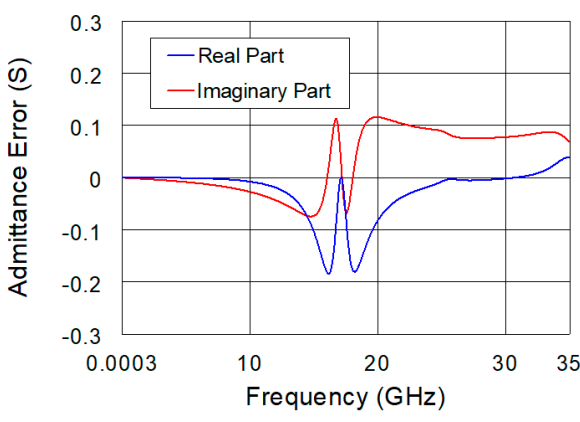

(a)

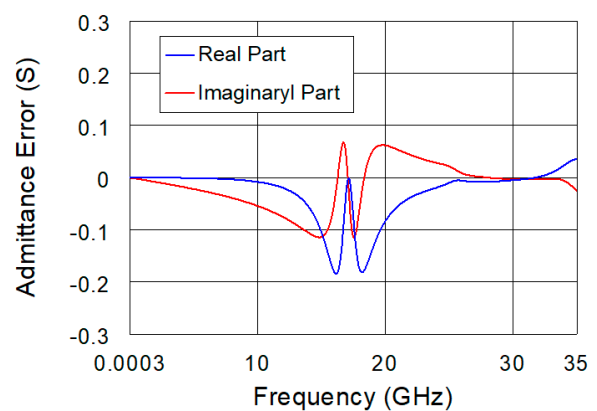

(b)

Figure 12. Difference between FEM and equivalent-circuit simulations of the real (blue lines) and imaginary parts (red lines) of the admittance from $0.3 \mathrm{MHz}$ to $35 \mathrm{GHz}$ for the IDC sensor loaded with a lossless MUT having a real part of the relative permittivity of 70: (a) equivalent-circuit simulations based on the local model and (b) equivalent-circuit simulations based on the modified broadband model.

\section{Conclusions}

A microfluidic biosensor based on a microwave one-port coplanar interdigital capacitor has been investigated for permittivity sensing. A FEM simulator has been used to simulate the sensor performance over the broad frequency range from $0.3 \mathrm{MHz}$ to $35 \mathrm{GHz}$ by considering lossless MUTs having different real part of the relative permittivity. The observed resonance in the sensor admittance has been reproduced by using the lumped-element equivalent-circuit approach. Furthermore, 
assessment of the sensor sensitivity to changes in the real part of the relative permittivity of the MUT has been accomplished by investigating the resonant frequency in the FEM simulations and the capacitance of the equivalent-circuit model. It has been shown that, by using the extracted capacitance instead of the resonant frequency as sensing parameter, the relative sensitivity of the sensor to changes in the real part of the relative permittivity results to be significantly enhanced. The significance of this study aimed at investigating and modeling an IDC sensor up to high frequencies stems from the following considerations: examination of broadband information is of crucial importance for the analysis of biological materials like cells, using only one sensor to obtain broadband information can make the platform very user-friendly and time-consuming, and the traditional IDC characterization model limits the application to low frequency range where the resonance is not necessary to consider. For future work, this full-blown simulation-based study will be extended through experimental characterization of real liquids, thus making the analysis more challenging but also much closer to practical applications, owing to inherent contributions of both losses and frequency dependence of the permittivity.

Author Contributions: Investigation, G.C. and X.B.; Methodology, G.C., X.B., and O.J.B.; Supervision, D.M.M.-P.S., and B.N.; Writing—original draft, G.C.; Writing—review and editing, X.B., O.J.B., D.M.M.-P.S., and B.N. All authors have read and agreed to the published version of the manuscript.

Funding: This research was supported in part by the KU Leuven research project C24/15/015 Microwave Microbiology ( $\mu 2 \mathrm{BIO}$ ) and in part by the Hercules project funding.

Conflicts of Interest: The authors declare no conflict of interest.

\section{References}

1. Piccolino, M. Luigi Galvani and animal electricity: Two centuries after the foundation of electrophysiology. Trends Neurosci. 1997, 20, 443-448. [CrossRef]

2. Li, C.; Peng, Z.; Huang, T.-Y.; Fan, T.; Wang, F.-K.; Horng, T.-S.; Muñoz-Ferreras, J.-M.; Gómez-García, R.; Ran, L.; Lin, J. A review on recent progress of portable short-range noncontact microwave radar systems. IEEE Trans. Microw. Theory Tech. 2017, 65, 1692-1706. [CrossRef]

3. Mercuri, M.; Soh, P.J.; Pandey, G.; Karsmakers, P.; Vandenbosch, G.A.E.; Leroux, P.; Schreurs, D.M.M.-P. Analysis of an indoor biomedical radar-based system for health monitoring. IEEE Trans. Microw. Theory Tech. 2013, 61, 2061-2068. [CrossRef]

4. Garripoli, C.; Mercuri, M.; Karsmakers, P.; Soh, P.J; Crupi, G.; Vandenbosch, G.A.E.; Pace, C.; Leroux, P.; Schreurs, D.M.M.-P. Embedded DSP-based telehealth radar system for remote in-door fall detection. IEEE J. Biomed. Health Inf. 2015, 19, 92-101. [CrossRef] [PubMed]

5. Álvarez López, Y.; García Fernández, M.; Grau, R.; Las-Heras, F. A synthetic aperture radar (SAR)-based technique for microwave imaging and material characterization. Electronics 2018, 7, 373. [CrossRef]

6. Mercuri, M.; Lorato, I.R.; Liu, Y.H.; Wieringa, F.; Van Hoof, C.; Torfs, T. Vital-sign monitoring and spatial tracking of multiple people using a contactless radar-based sensor. Nat. Electron. 2019, 2, 252-262. [CrossRef]

7. Whitesides, G.M. The origins and the future of microfluidics. Nature 2006, 442, 368-373. [CrossRef]

8. Chretiennot, T.; Dubuc, D.; Grenier, K. A microwave and microfluidic planar resonator for efficient and accurate complex permittivity characterization of aqueous solutions. IEEE Trans. Microw. Theory Tech. 2013, 61, 972-978. [CrossRef]

9. Abduljabar, A.A.; Clark, N.; Lees, J.; Porch, A. Dual mode microwave microfluidic sensor for temperature variant liquid characterization. IEEE Trans. Microw. Theory Tech. 2017, 65, 2572-2582. [CrossRef]

10. Bao, X.; Liu, S.; Ocket, I.; Bao, J.; Schreurs, D.M.M.-P.; Zhang, S.; Cheng, C.; Feng, K.; Nauwelaers, B. A general line-line method for dielectric material characterization using conductors with the same cross-sectional geometry. IEEE Microw. Wirel. Compon. Lett. 2018, 28, 356-358. [CrossRef] 
11. Mohd Bahar, A.A.; Zakaria, Z.; Md Arshad, M.K.; Alahnomi, R.A.; Abu-Khadrah, A.I.; Sam, W.Y. Microfluidic biochemical sensor based on circular SIW-DMS approach for dielectric characterization application. Int. J. RF Microw. Comput.-Aided Eng. 2019, 29, e21801. [CrossRef]

12. Markovic, T.; Bao, J.; Maenhout, G.; Ocket, I.; Nauwelaers, B. An interdigital capacitor for microwave heating at $25 \mathrm{GHz}$ and wideband dielectric sensing of $\mathrm{nL}$ volumes in continuous microfluidics. Sensors 2019, $19,715$. [CrossRef] [PubMed]

13. Liu, L.W.; Kandwal, A.; Cheng, Q.; Shi, H.; Tobore, I.; Nie, Z. Non-invasive blood glucose monitoring using a curved Goubau line. Electronics 2019, 8, 662. [CrossRef]

14. Yeo, J.; Lee, J.-I. High-sensitivity microwave sensor based on an interdigital-capacitor-shaped defected ground structure for permittivity characterization. Sensors 2019, 19, 498. [CrossRef] [PubMed]

15. Kremer, F. Dielectric spectroscopy-Yesterday, today and tomorrow. J. Non-Cryst. Solids 2002, 305, 1-9. [CrossRef]

16. Gabriel, C.; Gabriel, S.; Corthout, E. The dielectric properties of biological tissues: I. Literature survey. Phys. Med. Biol. 1996, 41, 22-31. [CrossRef]

17. Facer, G.R.; Notterman, D.A.; Sohn, L.L. Dielectric spectroscopy for bioanalysis: From $40 \mathrm{~Hz}$ to $26.5 \mathrm{GHz}$ in a microfabricated wave guide. Appl. Phys. Lett. 2001, 78, 996-998. [CrossRef]

18. Yokoyama, K.; Kamei, T.; Minami, H.; Suzuki, M. Hydration study of globular proteins by microwave dielectric spectroscopy. J. Phys. Chem. B 2001, 105, 12622-12627. [CrossRef]

19. Asami, K. Characterization of biological cells by dielectric spectroscopy. J. Non-Cryst. Solids 2002, 305, 268-277. [CrossRef]

20. Nikolova, N.K. Microwave imaging for breast cancer. IEEE Microw. Mag. 2011, 12, 78-94. [CrossRef]

21. Bellizzi, G.G.; Crocco, L.; Battaglia, G.M.; Isernia, T. Multi-frequency constrained SAR focusing for patient specific hyperthermia treatment. IEEE J. Electromagn. RfMicrow. Med. Biol. 2017, 1, 74-80. [CrossRef]

22. Artis, F.; Chen, T.; Chretiennot, T.; Fournie, J.-J.; Poupot, M.; Dubuc, D.; Grenier, K. Microwaving biological cells: Intracellular analysis with microwave dielectric spectroscopy. Ieee Microw. Mag. 2015, 16, 87-96. [CrossRef]

23. Daw, R.; Finkelstein, J. Lab on a chip. Nature 2006, 442, 367. [CrossRef]

24. Abgrall, P.; Gue, A. Lab-on-chip technologies: Making a microfluidic network and coupling it into a complete microsystem-A review. J. Micromech. Microeng. 2007, 17, R15-R49. [CrossRef]

25. Grenier, K.; Dubuc, D.; Poleni, P.-E.; Kumemura, M.; Toshiyoshi, H.; Fujii, T.; Fujita, H. Integrated broadband microwave and microfluidic sensor dedicated to bioengineering. IEEE Trans. Microw. Theory Tech. 2009, 57, 3246-3253. [CrossRef]

26. Grenier, K.; Dubuc, D.; Chen, T.; Artis, F.; Chretiennot, T.; Poupot, M.; Fournie, J.J. Recent advances in microwave-based dielectric spectroscopy at the cellular level for cancer investigations. IEEE Trans. Microw. Theory Tech. 2013, 61, 2023-2030. [CrossRef]

27. Meyne née Haase, N.; Fuge, G.; Trieu, H.K.; Zeng, A.-P.; Jacob, A.F. Miniaturized transmission-line sensor for broadband dielectric characterization of biological liquids and cell suspensions. IEEE Trans. Microw. Theory Tech. 2015, 63, 3026-3033. [CrossRef]

28. Bao, X.; Ocket, I.; Bao, J.; Doijen, J.; Zheng, J.; Kil, D.; Liu, Z.; Puers, B.; Schreurs, D.M.M.-P.; Nauwelaers, B. Broadband dielectric spectroscopy of cell cultures. IEEE Trans. Microw. Theory Tech. 2018, 66, 5750-5759. [CrossRef]

29. Bao, X.; Liu, S.; Ocket, I.; Liu, Z.; Schreurs, D.M.M.-P.; Nauwelaers, B. A modeling procedure of the broadband dielectric spectroscopy for ionic liquids. IEEE Trans. Nanobiosci. 2018, 17, 387-393. [CrossRef]

30. Bao, X.; Ocket, I.; Bao, J.; Liu, Z.; Puers, B.; Schreurs, D.M.M.-P.; Nauwelaers, B. Modeling of coplanar interdigital capacitor for microwave microfluidic application. IEEE Trans. Microw. Theory Tech. 2019, 67, 2674-2683. [CrossRef]

31. Kilpijärvi, J.; Halonen, N.; Juuti, J.; Hannu, J. Microfluidic microwave sensor for detecting saline in biological range. Sensors 2019, 19, 819. [CrossRef] [PubMed]

32. Mehrotra, P.; Chatterjee, B.; Sen, S. EM-Wave Biosensors: A review of RF, microwave, mm-wave and optical sensing. Sensors 2019, 19, 1013. [CrossRef] [PubMed] 
33. Starzyk, F. Parametrisation of interdigit comb capacitor for dielectric impedance spectroscopy. Arch. Mater. Sci. Eng. 2008, 34, 31-34.

34. Chen, T.; Dubuc, D.; Poupot, P.; Fournié, J.-J.; Grenier, K. Accurate nanoliter liquid characterization up to $40 \mathrm{GHz}$ for biomedical applications: Toward non-invasive living cells monitoring. IEEE Trans. Microw. Theory Tech. 2012, 60, 4171-4177. [CrossRef]

35. Su, W.; Cook, B.S.; Tentzeris, M.M. Additively manufactured microfluidics-based 'peel-and-replace' RF sensors for wearable applications. IEEE Trans. Microw. Theory Tech. 2016, 64, 1928-1936. [CrossRef]

36. Ruvio, G.; Vaselli, M.; Lopresto, V.; Pinto, R.; Farina, L.; Cavagnaro, M. Comparison of different methods for dielectric properties measurements in liquid sample media. Int. J. RF Microw. Comput.-Aided Eng. 2018, 28, e21215. [CrossRef]

37. Bao, X.; Ocket, I.; Crupi, G.; Schreurs, D.M.M.-P.; Bao, J.; Kil, D.; Puers, B.; Nauwelaers, B. A planar one-port microwave microfluidic sensor for microliter liquids characterization. IEEE J. Electromagn. RF Microw. Med. Biol. 2018, 2, 10-17. [CrossRef]

38. Vélez, P.; Muñoz-Enano, J.; Gil, M.; Mata-Contreras, J.; Martín, F. Differential microfluidic sensors based on dumbbell-shaped defect ground structures in microstrip technology: Analysis, optimization, and applications. Sensors 2019, 19, 3189. [CrossRef]

39. Crupi, G.; Bao, X.; Barmuta, P.; Ocket, I.; Schreurs, D.M.M.-P.; Nauwelaers, B. Microfluidic biosensor for bioengineering: High-frequency equivalent-circuit modeling of interdigital capacitor. In Proceedings of the IEEE International Conference on Telecommunications in Modern Satellite, Cable and Broadcasting Service (TELSIKS), Nis, Serbia, 23-35 October 2019; pp. 315-318.

40. Stojanović, G.; Paroški, M.; Samardžić, N.; Radovanović, M.; Krstić, D. Microfluidics-based four fundamental electronic circuit elements resistor, inductor, capacitor and memristor. Electronics 2019, 8, 960. [CrossRef]

41. Booth, J.C.; Orloff, N.D.; Mateu, J.; Janezic, M.; Rinehart, M.; Beall, J.A. Quantitative permittivity measurements of nanoliter liquid volumes in microfluidic channels to $40 \mathrm{GHz}$. IEEE Trans. Instrum. Meas. 2010, 59, 3279-3288. [CrossRef]

42. Alley, G. Interdigital capacitors and their application to lumped-element microwave-integrated circuits. IEEE Trans. Microw. Theory Tech. 1970, 18, 1028-1033. [CrossRef]

43. Van Gerwen, P.; Laureyn, W.; Laureys, W.; Huyberechts, G.; De Beeck, M.O.; Baert, K.; Suls, J.; Sansen, W.; Jacobs, P.; Hermans, L.; et al. Nanoscaled interdigitated electrode arrays for biochemical sensors. Sens. Actuators B Chem. 1998, 49, 73-80. [CrossRef]

44. Laureyn, W.; Van Gerwen, P.; Suls, J.; Jacobs, P.; Maes, G. Characterization of nanoscaled interdigitated palladium electrodes of various dimensions in $\mathrm{KCl}$ solutions. Electroanalysis 2001, 13, 204-211. [CrossRef]

45. Zhang, L.Y.; Landoulsi, A.; Bounaix, C.; du Punch, M.; Lacroix, A.; Dalmay, C.; Bessaudou, A.; Lautret, C.; Battu, S.; Lalloue, F.; et al. Label-free colorectal cancer cell line bio-sensing using RF resonator. In Proceedings of the IEEE International Conference on Solid-State Sensors, Actuators and Microsystems, Barcelona, Spain, 16-20 June 2013; pp. 1194-1197.

46. Bao, X.; Ocket, I.; Bao, J.; Kil, D.; Brancato, L.; Nauwelaers, B. Broadband dielectric spectroscopy measurements of liquids combining interdigital capacitor and coplanar waveguide. In Proceedings of the European Microwave Conference (EuMC), Nuremberg, Germany, 10-12 October 2017; pp. 946-949.

47. Booth, J.C.; Mateu, J.; Janezic, M.; Baker-Jarvis, J.; Beall, J.A. Broadband permittivity measurements of liquid and biological samples using microfluidic channels. In Proceedings of the IEEE MTT-S International Microwave Symposium Digest, San Francisco, CA, USA, 11-16 June 2006; pp. 1750-1753.

48. Ou, J.; Glawdel, T.; Ren, C.L.; Pawliszyn, J. Fabrication of a hybrid PDMS/SU-8/quartz microfluidic chip for enhancing UV absorption whole-channel imaging detection sensitivity and application for isoelectric focusing of proteins. Lab Chip 2009, 9, 1926-1932. [CrossRef]

49. Nihad, D.; Jehad, A.; Amjad, O. CAD modeling of coplanar waveguide interdigital capacitor. Int. J. RF Microw. Comput.-Aided Eng. 2005, 15, 551-558.

50. Rohdin, H.; Lee, G.S. Interfacial gate resistance in schottky-barrier-gate field-effect transistors. IEEE Trans. Electron Dev. 1998, 45, 2407-2416. [CrossRef] 
51. Crupi, G.; Raffo, A.; Vadalà, V.; Avolio, G.; Schreurs, D.M.M.-P.; Vannini, G.; Caddemi, A. Technologyindependent analysis of the double current-gain peak in millimeter-wave FETs. IEEE Microw. Wirel. Comp. Lett. 2018, 28, 326-328. [CrossRef]

52. Crupi, G.; Raffo, A.; Vadalà, V.; Vannini, G.; Caddemi, A. A new study on the temperature and bias dependence of the kink effects in $S_{22}$ and $h_{21}$ for the GaN HEMT technology. Electronics 2018, 7, 353. [CrossRef]

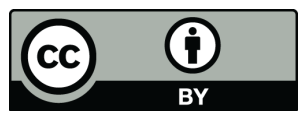

(C) 2020 by the authors. Licensee MDPI, Basel, Switzerland. This article is an open access article distributed under the terms and conditions of the Creative Commons Attribution (CC BY) license (http://creativecommons.org/licenses/by/4.0/). 